\title{
The critical condition and oscillation - transition characteristics of thermocapillary convection in the space experiment on SJ-10 satellite
}

\author{
Qi Kang ${ }^{\mathrm{a}, \mathrm{b}, 1}$, Huan Jiang ${ }^{\mathrm{a}, 1}$, Li Duan ${ }^{\mathrm{a}, \mathrm{b}, *}$, Chu Zhang ${ }^{\mathrm{a}}$, Wenrui Hu ${ }^{\mathrm{a}, \mathrm{b}}$ \\ ${ }^{a}$ Key Laboratory of Microgravity, Institute of Mechanics, Chinese Academy of Sciences, Beijing 100190, PR China \\ ${ }^{\mathrm{b}}$ School of Engineering Sciences, University of Chinese Academy of Sciences, Beijing 100049, PR China
}

\section{A R T I C L E I N F O}

\section{Article history:}

Received 12 July 2018

Received in revised form 23 January 2019

Accepted 31 January 2019

\section{Keywords:}

Space experiment

Thermocapillary convection

Oscillation

Bifurcation

Transition route

\begin{abstract}
A B S T R A C T
This paper is an investigation on oscillation characteristics and transition routes of thermocapillary convection in an annular liquid pool in the space experiment carried out on SJ-10 recoverable scientific experiment satellite. Thermocapillary convection caused by non-uniformity of surface tension and the instability problem of the convection are introduced, and the measurement by thermocouples has been analyzed in detail. Through the relationship between the critical condition of start-oscillation in thermocapillary convection and the volume ratio, and the relationship between the oscillation frequency and the volume ratio, transition processes from steady flow to oscillatory flow and then to bifurcation are investigated. In addition, the acting mechanism of thermocapillary force has been discussed comparing with buoyant-thermocapillary convection on the ground.
\end{abstract}

(c) 2019 Elsevier Ltd. All rights reserved.

\section{Introduction}

Since 1970s, with the development of manned space technology and the growing demands for high quality semiconductor and alloy materials in some modern hi-tech industries such as the microelectronics industry, crystal growth in the space microgravity environment has increasingly become an important application subject. Experimental results of multiple crystal growth indicate that the quality of grown crystals is unsatisfactory though there exists no adverse effects of physical processes such as density stratification and buoyancy convection in microgravity environment. In fact, because of the instability of thermocapillary convection in the process of the space crystal growth, the convection in the molten mass of crystals is liable to evolve into unsteady oscillatory convection, and the consequent temperature fluctuation will generate streak defects in crystals similar as what happened in ground situations. It becomes an urgent issue that restraining the generation of oscillatory thermocapillary convection and avoiding the appearance of streak defects, for improving the quality and efficiency of crystal growth in space as well as on the ground. Therefore, it is necessary to carry out in-depth studies on thermocapillary convection in order to better understand those processes and to provide reliable theory bases for relevant engineering technologies.

\footnotetext{
* Corresponding author.

E-mail address: duanli@imech.ac.cn (L. Duan).

1 Co-first authors.
}

Moreover, the research interest of people in thermocapillary convection is related to its complicated nonlinear dynamic characteristics. From the mechanism of thermocapillary flow we can see that it is a nonlinear flow phenomenon coupling the flow field with the temperature field, which means that thermocapillary convection can transit from a steady flow to another distinct steady flow with the change of control parameters, such as a transition from two-dimensional and axisymmetric flow to three-dimensional flow, a transition from steady convection to oscillatory convection, and a transition from periodic oscillatory convection to chaotic convection, and so on. Furthermore, it will eventually transit into turbulent flow same as other flow phenomena when control parameters exceed threshold conditions.

Thermocapillary convection is a challenging, valuable and interesting subject in the fundamental research field. And the instability of thermocapillary convection mainly manifests in three aspects: temperature, velocity and free surface displacement.

Theoretical and experimental studies on thermocapillary convection have been conducted for decades. As early as 1982, Ostrach [1] experimentally studied surface-tension induced convection in a cylindrical container by using methylene blue dyes to show the flow patterns. They conducted experiments in a drop tower with microgravity condition as well as in a normal gravitational environment, and the experimental results indicated that surface tension gradient at reduced gravity can be dominant and can generate flows as large as buoyancy induced flow at normal gravity. In 1983, Smith and Davis [2] performed a linear stability analysis on 
transition conditions of thermocapillary liquid layers ignoring buoyancy effects. Kamotani et al. [3,4] took velocity and temperature measurements to study experimentally the heat induced surface-tension driven flows in rectangular enclosures. Besides, experimental results were also compared with numerical solutions in their paper. In 1997, Favre et al. [5] simultaneously adopted measurement methods of shadowgraphy, thermocouples and LDV to study the instability of the buoyant-thermocapillarydriven flow in a cylindrical liquid layer which was locally heated. They found that the basic flow can lose stability and transit into different steady flow patterns as temperature difference is increased, then the flow patterns become time-dependent as temperature difference is further increased. In 1998, Mukolobwiez et al. [6] experimentally studied hydrothermal waves generated in the surface-tension-driven convection in an annular channel heated from the side wall through the shadowgraphy method. After convection transforms into hydrothermal waves, the flow can further transit from pure waves to a nonlinearly saturated modulation (a pure nonlinear phase mode), and then to an oscillatory mode with space-time defects. In 2001, Schatz \& Neitzel [7] made a thorough overview on studies of instabilities in freesurface flows driven by thermocapillarity. In addition, R. Grigoriev́s group [8-11] discussed buoyant-thermocapillary flow in confined geometries. These work using both numerical simulation and nonlinear stability analysis, discussed the effect of gas phase composition (phase change), Prandtl number Pr, dynamic Bond number $B d$ on the flow stability. In particular, the work pointed out the effect of phase change and gas phase which were usually ignored but could be significant for convection with volatile fluids, and discussed the effect of buoyancy. In recent years, Kang et al. [12,13] have carried out experimental research on thermocapillary convection in an open annular pool in ground-based conditions. Transitions of flow patterns and temperature oscillations in the flow field of buoyant-thermocapillary convection were observed, and flow instability rules and transition processes of the convection were analyzed and discussed. In particular, Kang et al. [14] have introduced thermocapillary convection experiment facility of the open cylindrical annuli for SJ-10 satellite.

There have been some reports about the research on transition routes of thermocapillary flow. In 1980, Gollub and Benson [15] experimentally studied various transition routes from laminar to turbulent flow in Rayleigh-Bénard convection. They observed four different transition routes to non-periodic motion by changing experimental parameters including the geometric aspect ratio, Prandtl number and mean flow: quasi-periodic motion with two frequencies phase-locking or entrainment, period-doubling bifurcations of a periodic flow, quasi-periodic motion with three generally incommensurate frequencies, and the process of intermittent non-periodicity. In 1993, Mukutmoni and Yang [16,17] performed numerical simulation on the bifurcation transition of RayleighBénard convection in a container with a small aspect ratio, and studied evolutions of velocity field and temperature field of the convection with the increase of $R a$ number. They reckoned that the transition to chaos observed in the simulations and experiments is similar to the period-doubling (Feigenbaum) route to chaos. In particular, the Feigenbaum route to chaos can be observed only if the oscillating velocity and temperature fields preserve the fourfold symmetry that is observed in the mean flow field of the horizontal plane, otherwise the transition route to chaos will become Ruelle-Takens-Newhouse. In 1995, Mukutmoni and Yang [18] reported the numerical study on bifurcation sequences in Rayleigh-Bénard convection. They observed a counter-intuitive transition route: steady state - periodic - quasi-periodic - steady state with the increase of Rayleigh number. In the same year, Tang and $\mathrm{Hu}$ [19] reported a numerical simulation on the transition process from steady convection to turbulence via subharmonic bifurcation in thermocapillary convection of a liquid bridge, and they studied the fractal feature of oscillatory convection in the half-floating zone. In 1999, Bucchignani and Stella [20,21] performed numerical study on mechanisms of transition processes to chaos in Rayleigh-Bénard convection. They have detected three different bifurcation sequences, and identified two individual mechanisms of transition to the non-periodic motion: the subharmonic cascade and the quasi-periodic flow with three incommensurate frequencies. In 2007, Rahal et al. [22] experimentally studied the transition process from steady to chaos in BénardMarangoni convection, and successively observed the monoperiodic, bi-periodic and chaotic states as the Marangoni number was increased. In addition, correlation dimensions of strange attractors corresponding to the chaotic regimes were calculated, and the transition from temporal chaos to spatio-temporal chaos was also observed. In 2010, Li et al. [23,24] reported numerical results about the transition process in double-diffusive Marangoni convection in a rectangular liquid pool with horizontal gradients in temperature and concentration. They found that the supercritical solution branch takes a quasi-periodic and phase-locking route to chaos, while the subcritical branch follows the Ruelle-TakensNewhouse scenario. Transient intermittency in the supercritical branch was observed and physical instability mechanisms of the subcritical branch were identified. Bucchignani and Mansutti $[25,26]$ reported their numerical analyses on oscillatory regimes and transition processes to chaos in thermocapillary convection in a rectangular liquid pool in 2000 and 2004 respectively. They used Rayleigh number $(R a)$ as the bifurcation parameter. A kind of periodic flow with a fundamental frequency appeared when $R a=4.25 \mathrm{e} 8$, and with the increase of $R a$ to $4.3 \mathrm{e} 8$, a second Hopf bifurcation happened in the convection with the transition from a periodic regime to a quasi-periodic regime with two incommensurate frequencies. When $R a=5 \mathrm{e} 8$, chaos arises following a transitory three-frequency quasi-periodic regime according to RuelleTakens-Newhouse route. In 2016, Li et al. [27] numerically studied bifurcation routes to chaos of thermocapillary convection in twodimensional liquid layers of finite extent, and they researched quasi-periodic routes and period-doubling cascades in different aspect ratios of the liquid layer.

At present, the research on chaos and turbulence of fluid is still a long-term and challenging subject. For an unknown nonlinear system, chaos is a ubiquitous phenomenon, and the chaos theory can explain the transition process from laminar flow to complicated turbulent flow. Kang et al. [28-29] have carried out research on transition issues of thermocapillary convection in rectangular liquid layers in detail. They have found several transition routes including quasi-periodic route, period-doubling bifurcation, quasi-periodic route accompanied with tangent bifurcation, period-doubling bifurcation accompanied with tangent bifurcation, and so on. The quasi-periodic route is a major and common transition route. The period-doubling bifurcation was observed in the floating half zone in the liquid bridge model by $\mathrm{Hu}$ et al. [30]

This article mainly introduces space experiments of thermocapillary convection on SJ-10 recoverable scientific experiment satellite. By comparing space experimental results and ground experimental results, the critical condition of start-oscillation and the characteristics of oscillation frequency in thermocapillary convection have been investigated in detail, and the transition process from steady flow to oscillatory flow has been analyzed particularly.

\section{The space experimental model and techniques}

The thermocapillary convection system in an annular liquid pool (Fig. 1) has been constructed by heating or cooling the fluid system in the space experiment, and the microgravity level of 


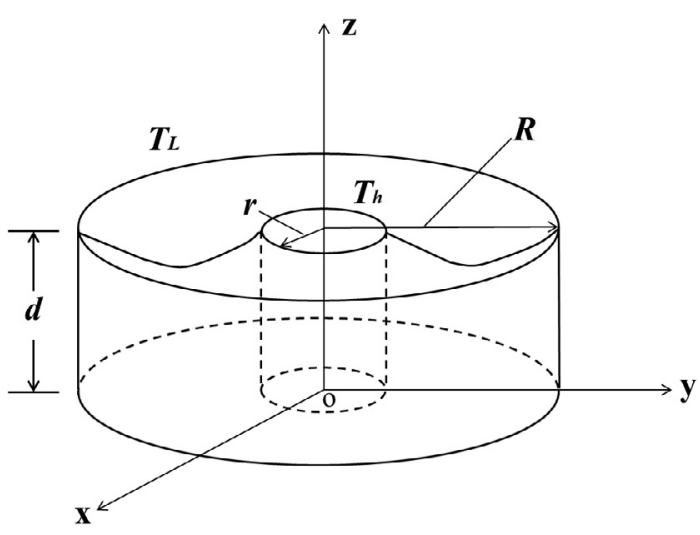

Fig. 1. The model diagram of the annular liquid pool.

the experiment is $10^{-3} \mathrm{~g}$. The dimensions of the annular pool are: the outer radius, $R=20 \mathrm{~mm}$, the inner radius, $r=4 \mathrm{~mm}$, the depth, $d=12 \mathrm{~mm}$, the difference between inner and outer radius, $L=R-r$. There is an electrothermal film inside the central cylinder for heating the fluid medium and semiconductor cooling plates attached to the outer surface of the annular wall in the annular pool. The temperature of the central cylinder is $T_{h}$, and the temperature of the outer wall is $T_{L}$. So the temperature difference between the inner and outer wall of the annular pool is $\Delta T=T_{h}-T_{L}$. Temperature on the inner and outer wall is measured by thermocouples and input to the temperature controller for being monitored and remote controlled. The heating and cooling can be performed according to the program. In addition, a wedge groove is designed on the internal surface of the outer wall, and at the same height, a wedge groove is designed on the external surface of the central cylinder, to prevent experimental fluid climbing along the solid wall under the action of surface tension in space experiments.

In space experiments, the fluid medium is 2cSt silicone oil of Shin-Etsu KF96 series, the evaporation rate of which is comparatively small in a limited experimental time. Its relevant physical properties are listed in Table 1 . Where, $\gamma$ is the kinematic viscosity, $\rho$ is the density of fluid, $\beta$ is the thermal-expansion coefficient, $\kappa$ is the thermal diffusivity, $\sigma$ is the surface tension, and $\sigma_{T}$ is the temperature coefficient of surface tension. In addition, $V$ denotes the volume of liquid in the annular pool, and $V_{0}$ denotes the capacity of the annular pool, $g$ is the gravitational acceleration. Relevant physical parameters are nondimensionalized as follows:

Volume ratio, $V r=V / V_{0}=V / \pi\left(R^{2}-r^{2}\right) d$, characterizes the volume effect of fluid;

Prandtl number, $P r=\frac{\gamma}{\kappa}$, characterizes the momentum exchange and the heat exchange in the fluid flow;

Marangoni number, $M a=\sigma_{T} \frac{\Delta T L}{\rho \gamma \kappa}$, characterizes the strength of thermocapillary convection;

Aspect ratio, $A r=d / L$, characterizes the size effect of fluid;

Dynamics Bond number, $B d=\frac{\rho g \beta d^{2}}{\sigma_{T}}$, characterizes the relative strength of buoyancy to surface tension.

The fluid medium is stored in a hydraulic cylinder before the experiment. At the beginning of the experiment, the working fluid in the hydraulic cylinder is injected into the annular pool driven by the stepper motor to construct the thermocapillary convection system. Meanwhile, the volume ratio of fluid could be precisely controlled by means of stepper motor injecting liquid to the liquid pool. The instability of thermocapillary flow can be represented by time evolution characteristics of some physical parameters such as temperature and free-surface deformation. Temperature is a key state variable reflecting the change of internal energy and the heat transfer process. In space experiment, we use thermocouples with high measurement sensitivity of $0.05{ }^{\circ} \mathrm{C}$ and measurement range of $-40{ }^{\circ} \mathrm{C}$ to $+125^{\circ} \mathrm{C}$. There are 6 thermocouple temperature sensors fixed inside the central cylinder of the annular liquid pool. These thermocouples pass through the central cylinder from the bottom of the liquid pool and come out from 6 apertures distributed on the central cylinder to measure fluid temperature. The 6 apertures are distributed in two circle lines of different heights on the central cylinder with 3 apertures on each circle line. The specific location of 6 temperature measuring points is shown in Fig. 2, T1-T6 represent the thermocouple 1-6.

There are two modes of heating, including the linear heating mode and the step heating mode in the space experiment of thermocapillary convection. In the course of experiments, temperature on both ends of the fluid layer is controlled through the predetermined linear heating mode. With the increase of temperature difference between two sides of fluid, thermocapillary flow gradually transits from steady state to unsteady state. During this process, temperature data of fluid are recorded by thermocouples, and then transferred to the ground. After experimental data being received, immediate data processing is required, and then next experiment condition including the mode of heating, the heating rate and the maximum temperature difference, etc. can be arranged based on previous space experimental results.

There are 23 series of space experiments of thermocapillary convection carried out on SJ-10 satellite, including 17 series of experiments with the linear heating mode and 6 series of experiments with the step-heating mode. The volume ratio of fluid ranges from 0.363 to 1.220 ; the maximum temperature differences between two sides of fluid are $25^{\circ} \mathrm{C}, 29^{\circ} \mathrm{C}, 30^{\circ} \mathrm{C}, 31^{\circ} \mathrm{C}, 34^{\circ} \mathrm{C}, 35^{\circ} \mathrm{C}$ and $40{ }^{\circ} \mathrm{C}$; the heating rates are $0.5^{\circ} \mathrm{C} / \mathrm{min}$ and $1.0^{\circ} \mathrm{C} / \mathrm{min}$. Temperature oscillations of thermocapillary convection at different volume ratios have been observed, which indicates the instability of thermocapillary convection is caused by the transition from steady state to oscillatory state.

\section{Results and discussions of space experiments}

\subsection{The critical condition and the fundamental frequency of start- oscillation}

A series of space experiments have been conducted through adjusting volume ratios of fluid and setting different experimental temperature differences, and a large number of measurements of thermocouples have been acquired. In every experiment, the temperature control stage is selected as the effective experimental stage. Therefore, only the measurement data of thermocouples in the temperature control stage is singled out to analyze, and zero time is the starting point of the temperature control stage. Take the experiment of the volume ratio of 0.834 as an example. The temperature measurement data by thermocouples at the volume ratio of 0.834 is shown in Fig. 3, where the black line denotes the temperature on the outer wall of the annular pool, which is the low temperature side of the fluid layer; the pink line denotes the

Table 1

The main physical parameters of 2cSt silicon oil

\begin{tabular}{|c|c|c|c|c|c|c|c|}
\hline Silicon oil & $\gamma, \mathrm{m}^{2} / \mathrm{s}$ & $\rho, \mathrm{kg} / \mathrm{m}^{3}$ & $\beta, 1 /{ }^{\circ} \mathrm{C}$ & $\kappa, \mathrm{m}^{2} / \mathrm{s}$ & $\sigma, \mathrm{N} / \mathrm{m}$ & $\sigma_{\mathrm{T}}, \mathrm{N} /\left(\mathrm{m} \cdot{ }^{\circ} \mathrm{C}\right)$ & $\mathrm{Pr}$ \\
\hline $2 \mathrm{cSt}$ & $2.00 \times 10^{-6}$ & $8.73 \times 10^{2}$ & $1.24 \times 10^{-3}$ & $7.00 \times 10^{-8}$ & $1.83 \times 10^{-2}$ & $-7.15 \times 10^{-5}$ & 28.57 \\
\hline
\end{tabular}




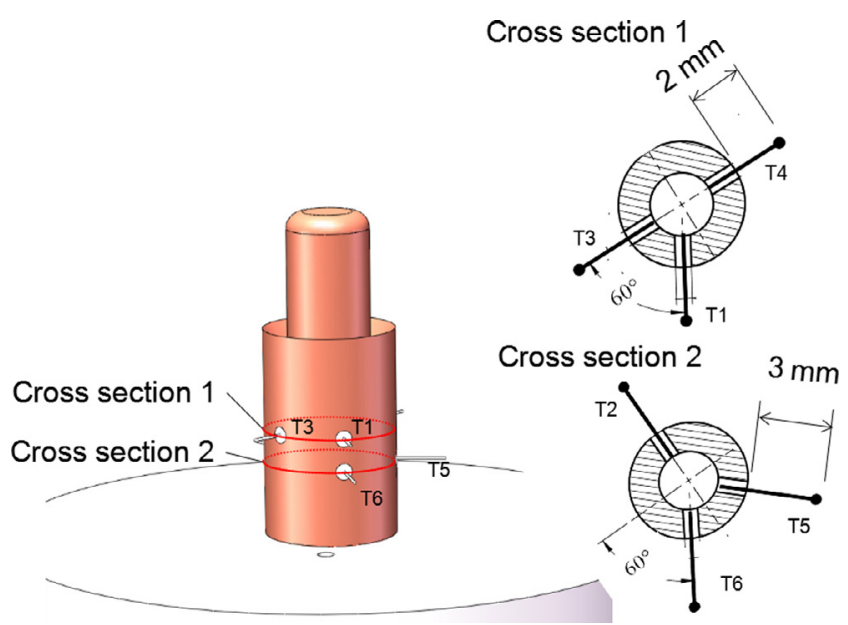

Fig. 2. The installation location of thermocouples.

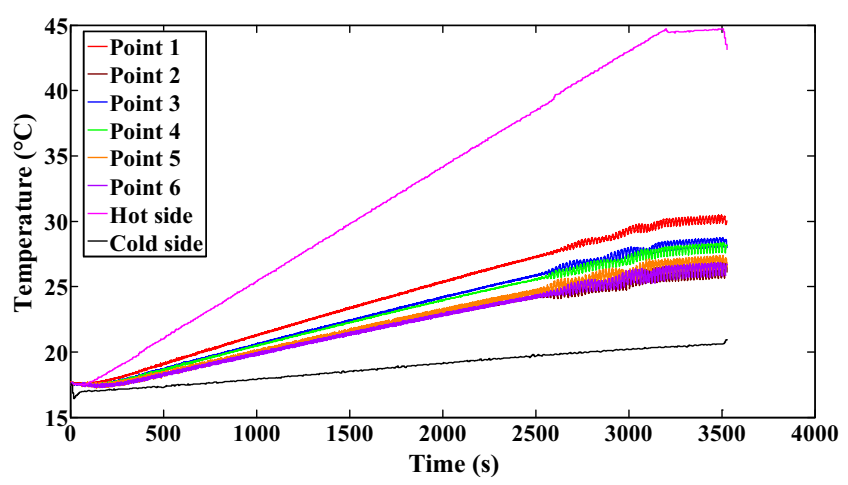

Fig. 3. Time evolution of thermocouple temperature oscillations in the stage of temperature control at the volume ratio of 0.834 .

temperature variation with the heating rate of $0.5^{\circ} \mathrm{C} / \mathrm{min}$ on the central cylinder, which is the high temperature side of the fluid layer. When the temperature difference between two sides of the fluid layer increases, temperature data of 6 points in the fluid is recorded with 6 thermocouples. As shown in the figure, when the temperature difference is small, temperature values at measured points increase linearly; when the temperature difference exceeds a threshold, the temperature in fluid starts oscillating regularly, and the oscillation has been stable and shows a variety of transformations with the increasing of temperature difference, until the end of the experiment. In addition, as shown in Fig. 3, temperature oscillations of six measuring points appear nearly simultaneously at the same temperature difference in experiments. The volume ratios, critical temperature differences, fundamental frequencies of start-oscillation and heating conditions in the 23 space experiments are listed in Appendix A.

In space experiments of thermocapillary convection, the critical temperature difference varies with the volume ratio, and the dynamics Bond number, $B d$, is equal to 0 in the circumstances. The critical temperature difference can be nondimensionalized to the critical Marangoni number, $M a_{c}$. The variation characteristics of the critical Marangoni number, $M a_{c}$, vs the volume ratio, $V r$, in different experimental conditions is shown in Fig. 4: the critical curve based on the least square method can be divided into two sections with the cut-off point at the volume ratio of $0.634 . M a_{c}$ increases with the increase of the volume ratio in the left part of the curve, while $M a_{c}$ decreases with the increase of the volume ratio in the right part. The flow regime is laminar flow under the

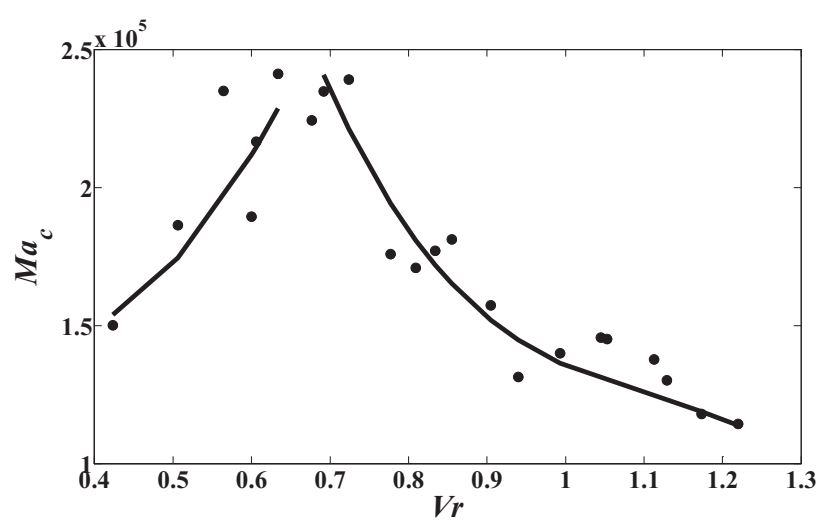

Fig. 4. The critical Marangoni number of temperature oscillation $M a_{c}$ vs. the volume ratio $V r$ in space experiments $(B d=0)$.

critical curve, whereas the flow starts to transit to chaos or turbulence above the curve. From the curve we can see that thermocapillary convection is the most stable when the volume ratio is around 0.634 in microgravity environment.

Whereas in ground-based experiments, the critical Marangoni number $M a_{c}$ changes with the dynamics Bond number $B d$ (the aspect ratio $A r$ ). In ground-based experiments, the identical experimental model in structure and size is adopted, and the experimental fluid is also precisely the same. Besides, we adopts the uniform heating mode and the same measuring method in experiments. Fig. 5 shows the curve of critical Marangoni number of temperature oscillation with the dynamics Bond number (small aspect ratios), and the curve presents a U-shape pattern. Under the influence of gravity, for the thick liquid layer with $B d$ exceeding 0.52 , the buoyancy effect is dominant in the convection, as a result, it is hard to start oscillation in the flow. For the thinner liquid layer, thermocapillary force is dominant in the convection, and the oscillation is liable to appear in the convection when the temperature difference between two sides of the fluid layer exceeds a threshold value. However, for the thin liquid layer with $B d$ less than 0.15 , the oscillation starts late in the convection due to the wall effect.

From the comparison between space experiments and groundbased experiments, $M a_{c}$ of the temperature oscillation in space experiments is comparatively small, which signifies that thermocapillary convection is liable to loose stability and start to oscillate in microgravity environment. Besides, in space experiments, when the volume ratio of fluid is sufficiently small (less than 0.6 ), the flow is liable to be affected by the solid boundary. While the volume ratio of fluid is greater than 0.6 , thermocapillary convection depends on volume ratio effects.

In general, in the space experiment, the convection firstly goes through a process of periodic oscillation for a long period of time

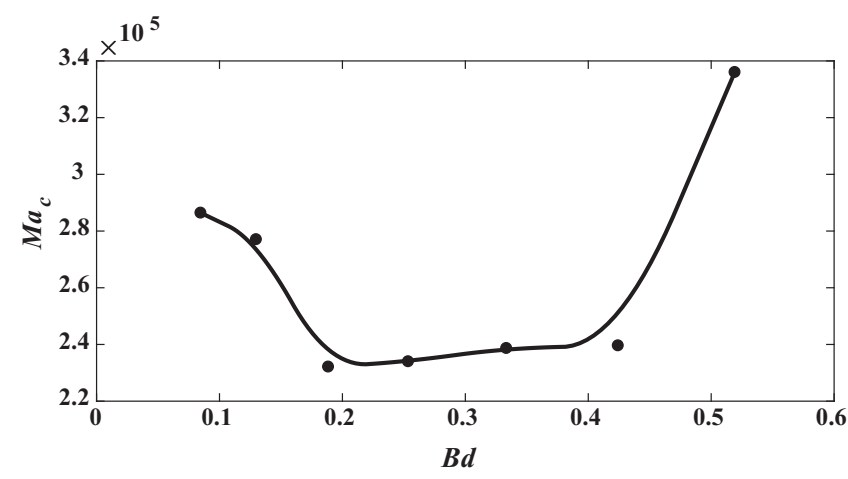

Fig. 5. The critical Marangoni number of temperature oscillation $M a_{c}$ vs. the dynamics Bond number $B d$ in ground-based experiments $(0.06<A r<0.16)$. 
after the temperature difference exceeds a threshold value. Then further complex oscillations may appear in some experiments. Fundamental frequencies of start-oscillation differ in experiments with various volume ratios, and as shown in Fig. 6, the fundamental frequency of temperature oscillation, denoted as $f$, decreases with the increase of the volume ratio. Compared with groundbased experiments in Fig. 7, the effect of buoyancy convection can influence the monotonicity of the fundamental frequency variation. Moreover, the oscillation frequency in space experiments is less than that in ground-based experiments with one order of magnitude, which also further illustrates that thermocapillary convection is more slow in microgravity environment. In fact, under the condition of microgravity, the buoyancy convection is greatly suppressed, and the thermocapillary force drives the convection. A relatively onefold external experimental condition will not give rise to intense the convection. Therefore, the oscillation frequency of thermocapillary convection in space is significantly less than that in ground experiments.

\subsection{Transition and transition routes}

As is well-known, steady flow gradually evolves into disordered turbulence as the temperature difference of fluid increases. It is particularly important to investigate the transition route of thermocapillary convection in the annular liquid pool as the typical fluid model of microgravity. Space experiments provide us a good research environment for research on the instability mechanism of thermocapillary convection.

In the spectrum analyses on temperature oscillation for each group of thermocouple measurements, two main transition routes have been observed, which are the period-doubling bifurcation and the quasi-periodic route. In addition, there exist some exceptional oscillations, however, we could not observe overall transition processes because of the temperature control limit on the space experimental model. Throughout 23 series of space experimental results, generally speaking, the fundamental frequency of temperature oscillation increases with the increase of temperature difference during each experiment, and the periodic oscillation is ubiquitous. In addition, there are several experiments in which quasi-periodic oscillations (at volume ratios of 1.045 and 0.855 ) and period-doubling oscillations (at volume ratios of 0.564 ) appeared, and the distribution of volume ratios is broad in different transition routes.

\section{(1) The steady periodic oscillation}

In microgravity environment, it maintains the periodic oscillation state for a long time after the oscillation starts to appear in the convection, and the fundamental frequency of oscillation

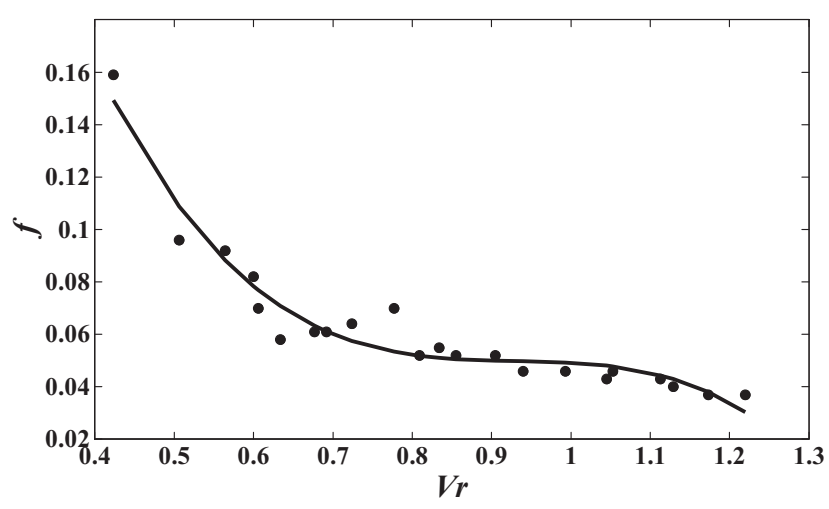

Fig. 6. Fundamental frequency of start-oscillation of temperature periodic oscillation $f$ vs. the volume ratio $V r$ in space experiments $(B d=0)$.

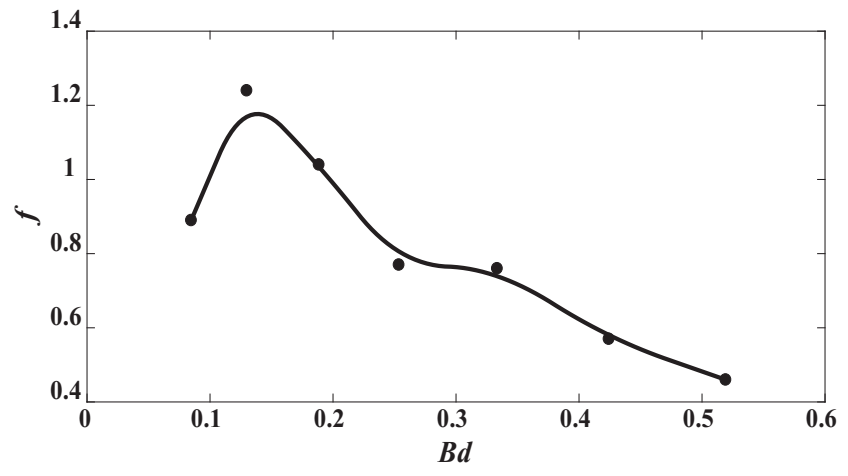

Fig. 7. Fundamental frequency of start-oscillation of temperature periodic oscillation $f$ vs. the dynamics Bond number $B d(0.06<A r<0.16)$ in ground-based experiments.

increases as the temperature difference increases. In fact, we can only observe this periodic oscillation state in most experiments.

The time evolution of temperature oscillation at the volume ratio of 0.834 has been shown in Fig. 3. In this experiment, the linear heating mode has been adopted and the temperature difference is increased to $25^{\circ} \mathrm{C}$. The oscillation signals of thermocouples are steady through the whole experiment, and they maintain the onefold regular oscillation state after oscillation starts to appear in the convection until the end of the experiment. In this experiment, fluid temperature data of thermocouple 4 is selected for spectrum analysis, shown in Fig. 8. The regular periodic oscillation appears in the convection when the temperature difference is at $22.02{ }^{\circ} \mathrm{C}$ and $24.07^{\circ} \mathrm{C}$. As the temperature difference increases, the convection is more and more intensive, which results in the increase of fundamental frequency of oscillation, $f_{1}$. $f_{1}$ increases from $0.055 \mathrm{~Hz}$ at the beginning to $0.061 \mathrm{~Hz}$ in the end, while the amplitude of oscillation has no significant change. Due to different measuring positions of other 5 thermocouples, the magnitudes of temperature data are different, but the oscillation characteristics are in full accord, which also indicates that the flow characteristics in the whole flow field is identical.

The step-heating mode is adopted in the experiment at the volume ratio of 0.692 . As shown in Fig. 9, the pink line that denotes temperature on the hot side increases steadily and each section of constant value in temperature is the heating step. There are four steps in the experimental process, and the temperature difference is, in order, $19{ }^{\circ} \mathrm{C}, 22^{\circ} \mathrm{C}, 26^{\circ} \mathrm{C}$ and $31^{\circ} \mathrm{C}$. From the curves of temperature measured by thermocouples in the fluid, we can see that no oscillation has occurred in the convection in the first two steps, and periodic oscillation starts to appear in the third step and last until the end of the experiment. As shown in the power spectrum analyses in Fig. 10, the fundamental frequency of temperature oscillation is $0.061 \mathrm{~Hz}$ in the third step, and the fundamental frequency is $0.064 \mathrm{~Hz}$ in the fourth step.

Most space experiments have similar results as the above two experiments. As the temperature difference increases, the fundamental frequency just increases but the second fundamental frequency or the period-doubling fractional frequency does not appear in the power spectrum. This is because that oscillation develops more slowly in pure thermocapillary convection in space than in buoyant-thermocapillary convection on ground. As a result, it can maintain the periodic oscillation state within a more extensive range of temperature difference.

\section{(2) The quasi-periodic route}

In the space experiment at volume ratio of 1.045 , the linear heating mode has been adopted and the temperature difference between two sides of the fluid layer has been increased to $35^{\circ} \mathrm{C}$, 

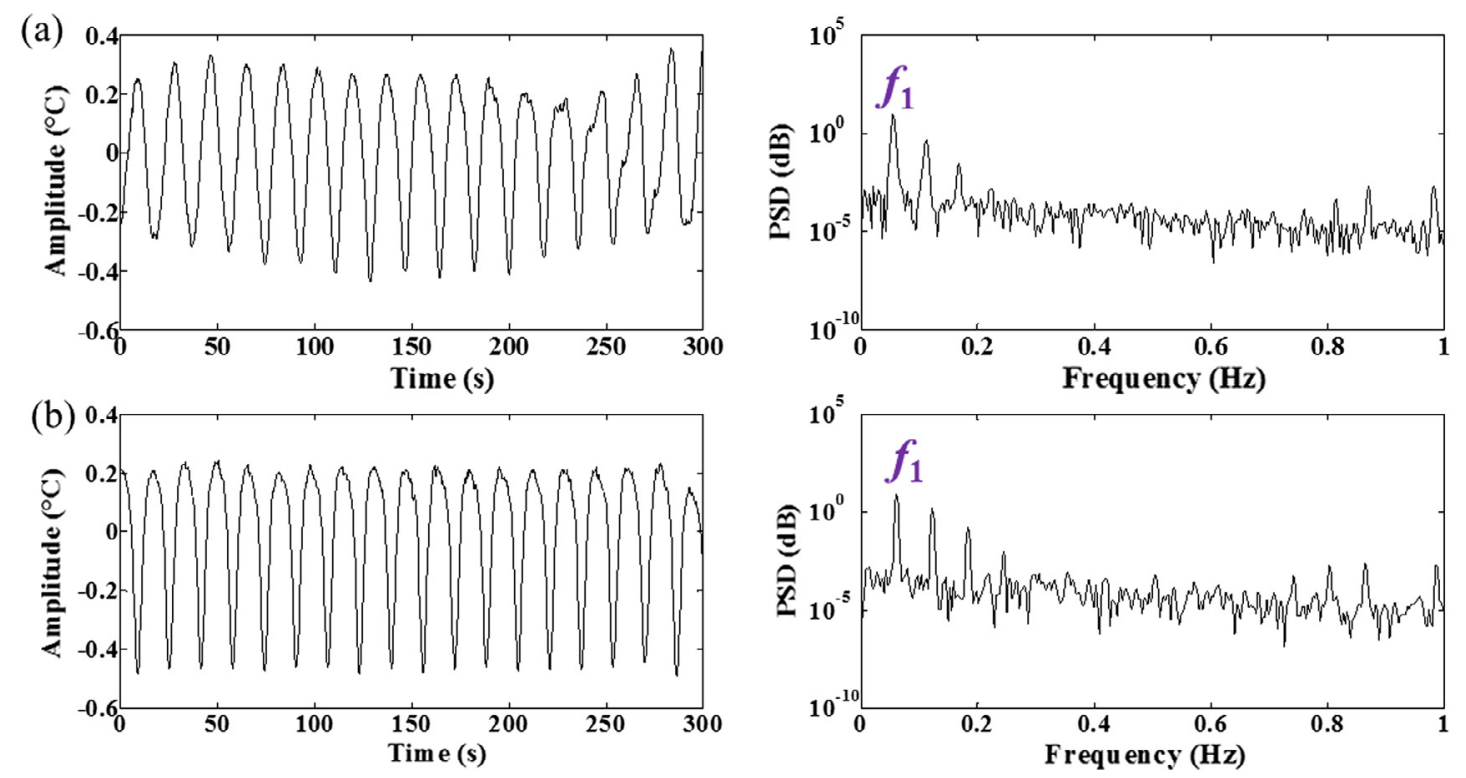

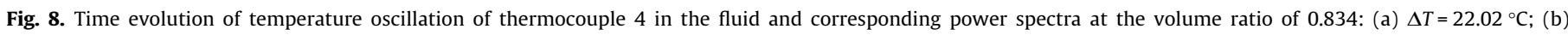
$\Delta T=24.07{ }^{\circ} \mathrm{C}$.

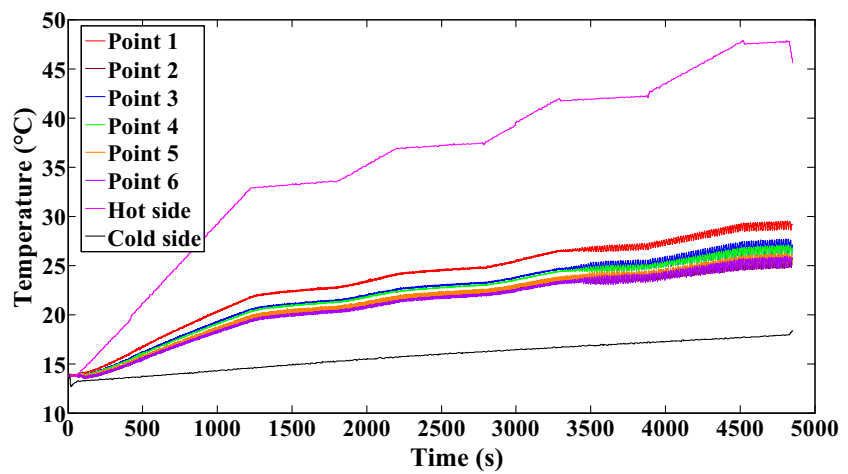

Fig. 9. Time evolution of temperature oscillation of thermocouples at the volume ratio of 0.692 .

shown in Fig. 11. In this experiment, after the six temperature measured by thermocouples in the fluid starts to oscillate, the convection goes through the transition process from periodic oscillation to quasi-periodic oscillation with two incommensurate frequencies with the increase of temperature difference. The evolutionary process of temperature oscillation in the convection can be illustrated by a time-frequency spectrum as shown in Fig. 12. Different frequencies of temperature oscillation gradually appear in the timefrequency spectrum with the increase of the temperature difference (experimental time growth in Fig. 12). The abscissa denotes the frequency of oscillation, and the ordinate denotes the experimental time corresponding to the time axis in Fig. 11. As shown in the time-frequency spectrum, when it is at about $2000 \mathrm{~s}$, in other words, the temperature difference between two sides of the fluid layer is about $15.55^{\circ} \mathrm{C}$, temperature oscillation with the fundamental frequency of $f_{1}$ starts to appear and the convection turns into the periodic oscillation state. As the temperature difference increases to $29.03^{\circ} \mathrm{C}$, which is the location close to $4000 \mathrm{~s}$ in the timefrequency spectrum, the second fundamental frequency $f_{2}$ appears and the convection transits to the state of quasi-periodic route with two incommensurate frequencies, until the experiment is finished when the temperature difference is $33.26^{\circ} \mathrm{C}$.

In the space experiment, after the start-oscillation of temperature, the convection keeps in the state of periodic oscillation for a long time, and then transits into the quasi-periodic stage with two incommensurate frequencies, until the end of the experiment. Whereas in the experiments with small aspect ratios on the ground, the critical temperature difference of start-oscillation in the convection is higher and the time interval from periodic oscillation to quasi-periodic oscillation is shorter due to the influence of buoyancy convection. In other words, in most of space experiments, the convection is tend to further transit through bifurcation as long as enough temperature differences and enough experimental times in microgravity environment.

The power spectrum analyses on temperature oscillation are shown in Fig. 13 (measured by thermocouple 1 in the fluid, for example). At the beginning of oscillation in the convection, the mean temperature difference is $17.38^{\circ} \mathrm{C}$, and the fundamental frequency of temperature oscillation $f_{1}$ is $0.043 \mathrm{~Hz}$. In addition, there are also several multiples of the fundamental frequency, such as $2 f_{1}: 0.085 \mathrm{~Hz}$ and $3 f_{1}: 0.128 \mathrm{~Hz}$. As the temperature difference is increased to $21.29^{\circ} \mathrm{C}$, the oscillation is in periodic state and more multiples of the fundamental frequency appear in the power spectrum. By this time, the fundamental frequency $f_{1}$ has increased to $0.046 \mathrm{~Hz}$, and other frequency multiples in turn are $0.092 \mathrm{~Hz}, 0.137 \mathrm{~Hz}$ and $0.183 \mathrm{~Hz}$. As the temperature difference is increased to $29.41^{\circ} \mathrm{C}$, the second fundamental frequency $f_{2}$ of $0.063 \mathrm{~Hz}$ starts to appear in the power spectrum, which indicates that the convection is in quasi-periodic state with two incommensurate frequencies. At this moment, the first fundamental frequency $f_{1}$ continues to increase to $0.052 \mathrm{~Hz}$, and all other frequencies can be expressed by the linear combination of the two incommensurable fundamental frequencies $f_{1}$ and $f_{2}$. Until the temperature difference is as high as $33.61^{\circ} \mathrm{C}$, the convection is still in quasi-periodic state with two incommensurate frequencies, with the first fundamental frequency $f_{1}$ of $0.053 \mathrm{~Hz}$ and the second fundamental frequency $f_{2}$ of $0.066 \mathrm{~Hz}$, and other frequencies of $0.014\left(f_{2}-f_{1}\right) \mathrm{Hz}, 0.041\left(2 f_{1}-f_{2}\right) \mathrm{Hz}, 0.078\left(2 f_{2}-f_{1}\right) \mathrm{Hz}, 0.096$ $\left(3 f_{1}-f_{2}\right) \mathrm{Hz}, 0.107\left(2 f_{1}\right) \mathrm{Hz}, 0.119\left(f_{1}+f_{2}\right) \mathrm{Hz}, 0.131\left(2 f_{2}\right) \mathrm{Hz}, 0.1495$ $\left(4 f_{1}-f_{2}\right) \mathrm{Hz}, 0.172\left(2 f_{1}+f_{2}\right) \mathrm{Hz}, 0.185\left(f_{1}+2 f_{2}\right) \mathrm{Hz}$, and so on.

\section{(3) The period-doubling bifurcation}

The step-heating mode has been adopted in the experiment at the volume ratio of 0.564 , temperature differences of four steps, 

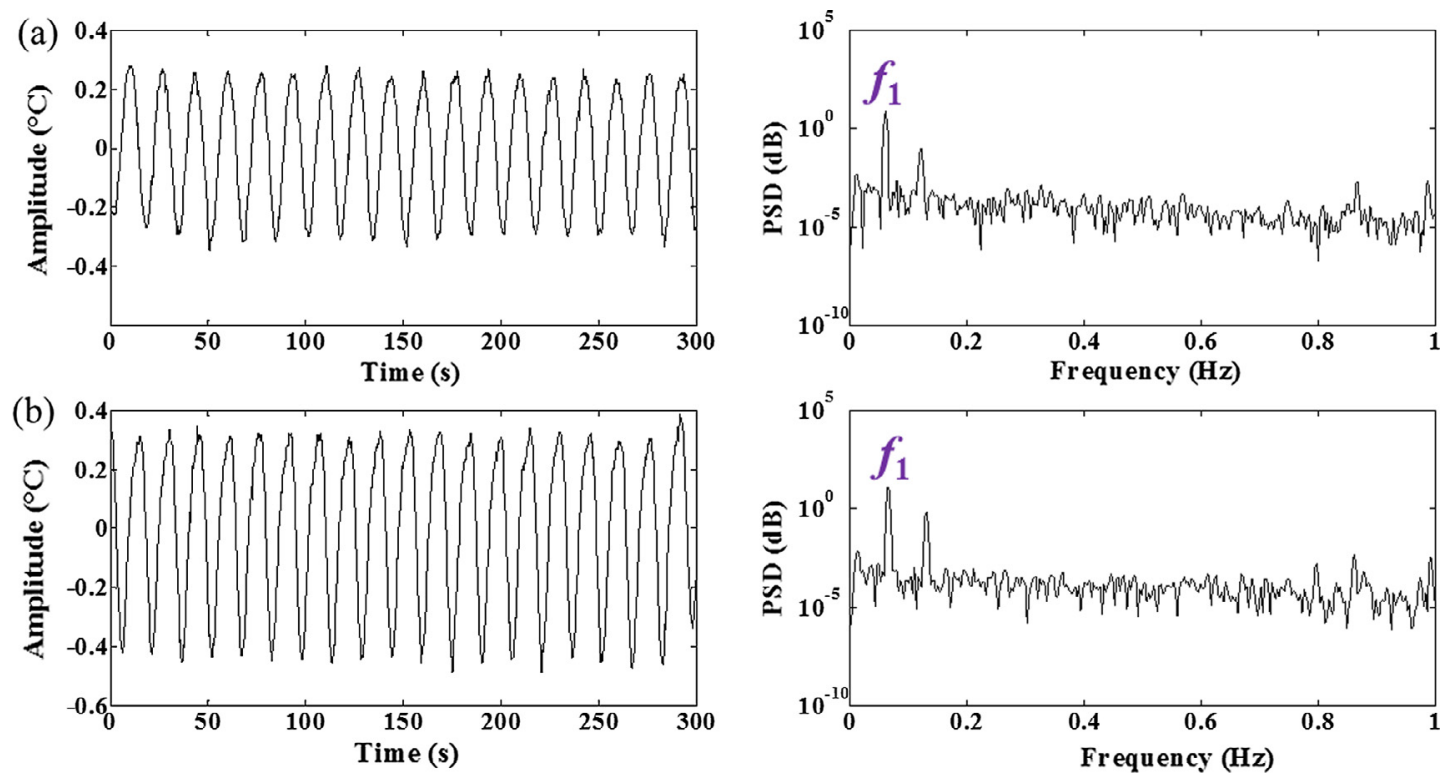

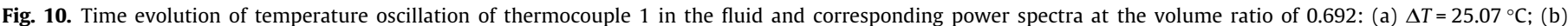
$\Delta T=29.86^{\circ} \mathrm{C}$.

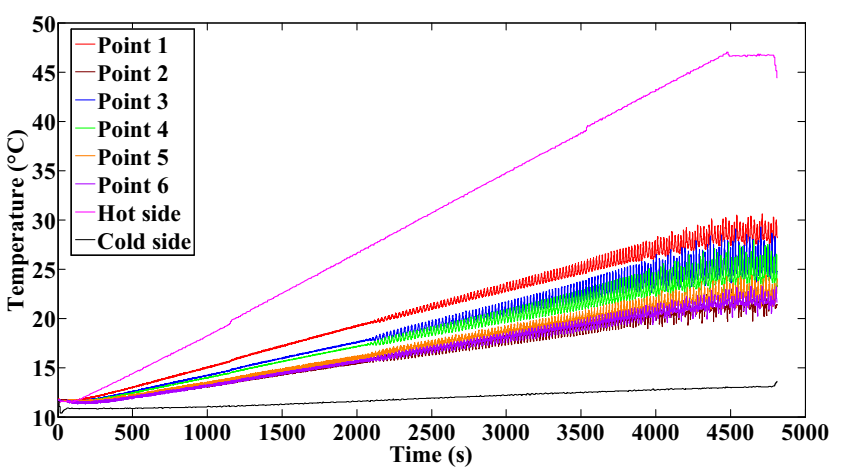

Fig. 11. Time evolution of temperature oscillation measured by thermocouples at the volume ratio of 1.045 .

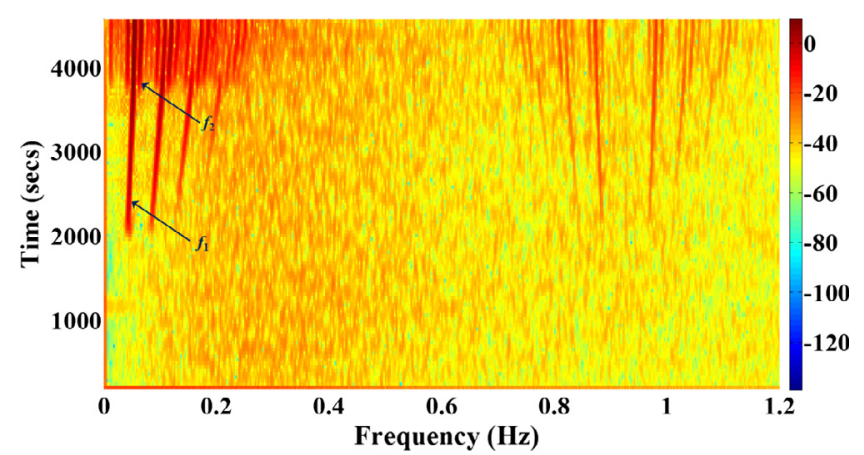

Fig. 12. Time-frequency spectrum of temperature oscillation measured by thermocouple 1 in the fluid at the volume ratio of 1.045 .

in turn, are $26^{\circ} \mathrm{C}, 27^{\circ} \mathrm{C}, 28^{\circ} \mathrm{C}$ and $30^{\circ} \mathrm{C}$, shown in Fig. 14 . Similarly, we can study the development of convective oscillation through time-frequency spectra in this experiment. As shown in Fig. 15, the fundamental frequency $f_{1}$ appears when the experimental time is close to $2000 \mathrm{~s}$ after the beginning, which means periodic oscillation starts to appear in the convection. Shortly after $2000 \mathrm{~s}$, the frequency whose magnitude is half of the fundamental frequency, $1 / 2 f_{1}$, appears in the time-frequency spectrum, which indicates that the convection has transited to the oscillatory regime of $1 / 2$ period-doubling bifurcation. The temperature oscillation data of thermocouples 4 and 5 in the fluid has been selected for the power spectrum analyses, as shown in Figs. 16 and 17. The flow starts oscillating periodically on the first step (the temperature difference of $25.11^{\circ} \mathrm{C}$ ), and the fundamental frequency $f_{1}$ of $0.092 \mathrm{~Hz}$ and the sub-harmonic $2 f_{1}$ of $0.186 \mathrm{~Hz}$ appears in the power spectrum. On the second step (the temperature difference of $26.08{ }^{\circ} \mathrm{C}$ ), the $1 / 2$ period-doubling bifurcation appears, and the convection transits into $1 / 2$ period-doubling oscillatory regime, and there exist the fundamental frequency $f_{1}$ of $0.093 \mathrm{~Hz}$ and sub-harmonics, $1 / 2 f_{1}$ of $0.047 \mathrm{~Hz}, 3 / 2 f_{1}$ of $0.139 \mathrm{~Hz}$ and $2 f_{1}$ of $0.186 \mathrm{~Hz}$ at the moment. On the third step (the temperature difference of $27.04^{\circ} \mathrm{C}$ ), the convection turns into the periodic oscillation regime again, and the fundamental frequency is $f_{1}=0.095 \mathrm{~Hz}$, and sub-harmonics are $2 f_{1}=0.189 \mathrm{~Hz}$ and $3 f_{1}=0.284 \mathrm{~Hz}$. On the forth step (the temperature difference of $28.97{ }^{\circ} \mathrm{C}$ ), the convection keeps in the periodic oscillation regime, and the fundamental frequency is $f_{1}=0.098 \mathrm{~Hz}$, and sub-harmonics are $2 f_{1}=0.192 \mathrm{~Hz}$ and $3 f_{1}=0.290 \mathrm{~Hz}$. In a word, in this experiment, the period-doubling bifurcation appears on the second step. This bifurcation does not continue to develop and the convection returns to the periodic oscillation state with the increase of the temperature difference. Actually, in our ground-based experiments, the transition route of period-doubling bifurcation $[28,29,31,32]$ has been observed and studied in detail for many times. However, there are discrepancies between results in space experiments and that in groundbased experiments, which means that the flow driven only by thermocapillary force in the microgravity environment tends to be steady without the influence of buoyancy. And the state of period-doubling bifurcation is unstable under the onefold driving effect of surface tension in convection. While on the ground, the coupling of thermocapillary force with buoyancy makes the bifurcation appear shortly after the convection evolves into oscillatory state, and then the convection transits into the chaotic state quickly.

In addition, from temperature oscillations in Figs. 16 and 17, we found that amplitudes of temperature oscillation in different locations of the fluid layer differ from each other. Compared to thermocouple 5 in the fluid, thermocouple 4 in the fluid is closer to the heating cylinder. The corresponding amplitude of temperature 

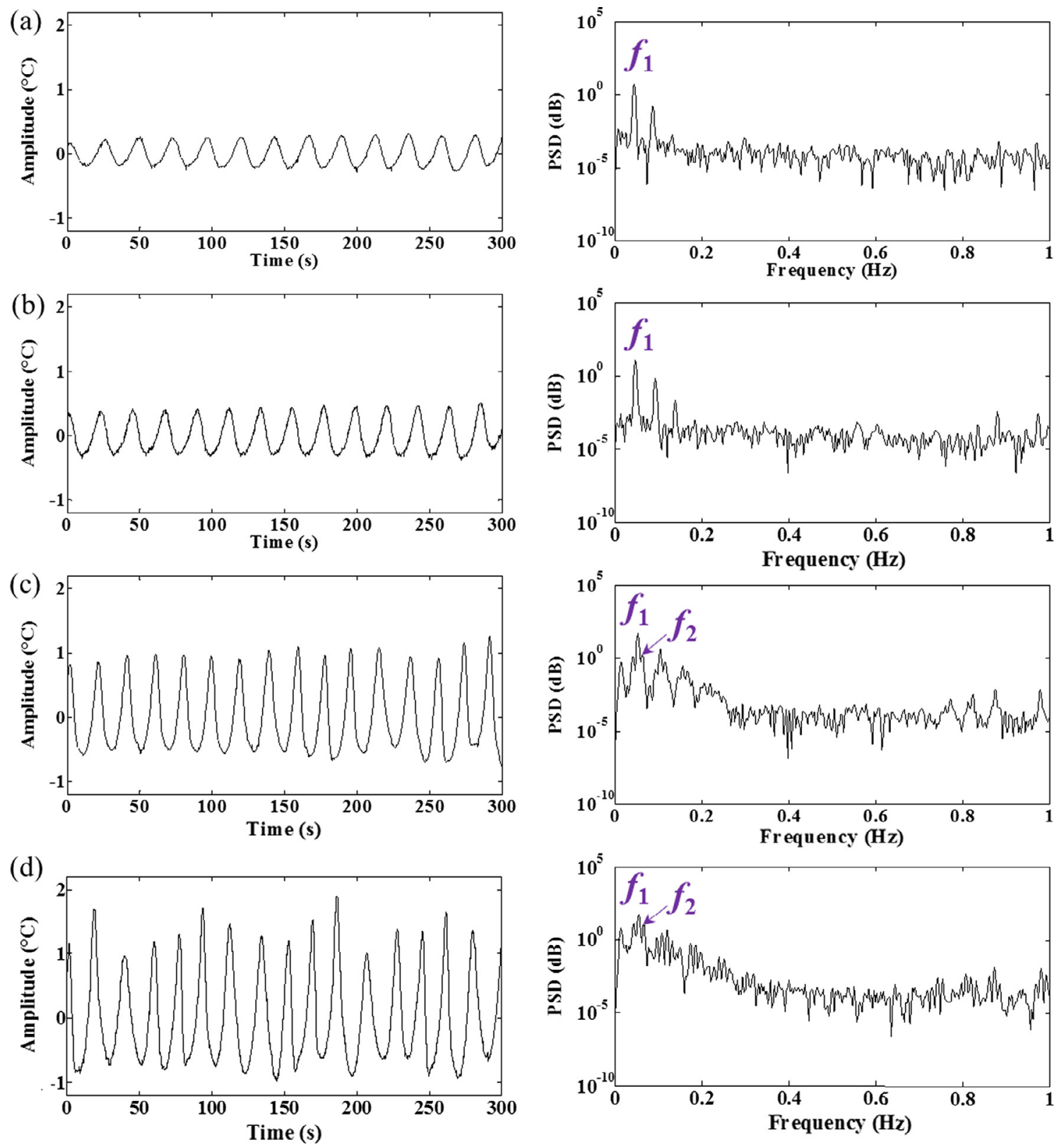

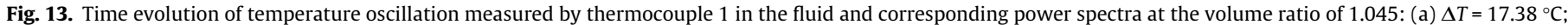
(b) $\Delta T=21.29^{\circ} \mathrm{C}$; (c) $\Delta T=29.41^{\circ} \mathrm{C}$; (d) $\Delta T=33.61{ }^{\circ} \mathrm{C}$.

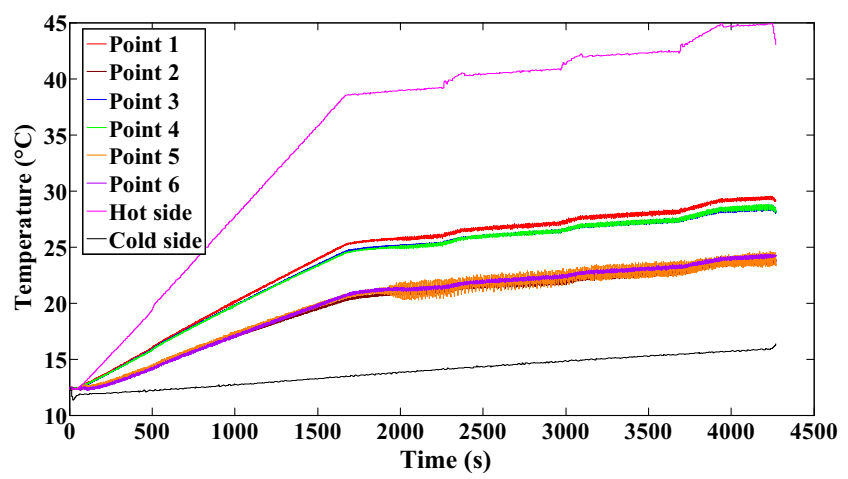

Fig. 14. Time evolution of temperature oscillation measured by thermocouples at the volume ratio of 0.564 . oscillation measured by thermocouple 4 is relatively small. This further illustrates that the spectrum characteristics of temperature oscillation can be identical though the amplitudes of oscillation differ in different measuring locations.

\section{(4) Intermittency}

An intermittent phenomenon has been observed in the experiment at the volume ratio of 0.606 . The step-heating mode is adopted in this experiment, and temperature differences of four steps, in turn, are $24^{\circ} \mathrm{C}, 27^{\circ} \mathrm{C}, 30^{\circ} \mathrm{C}$ and $34^{\circ} \mathrm{C}$. As shown in Fig. 18, the periodic oscillation appears and lasts for a short time on the first step, then the temperature oscillation signal turns to be chaotic at the end of the first step, and at this moment, the convection turns into aperiodic oscillation state and maintains in this state for a long time. As the temperature difference increases 


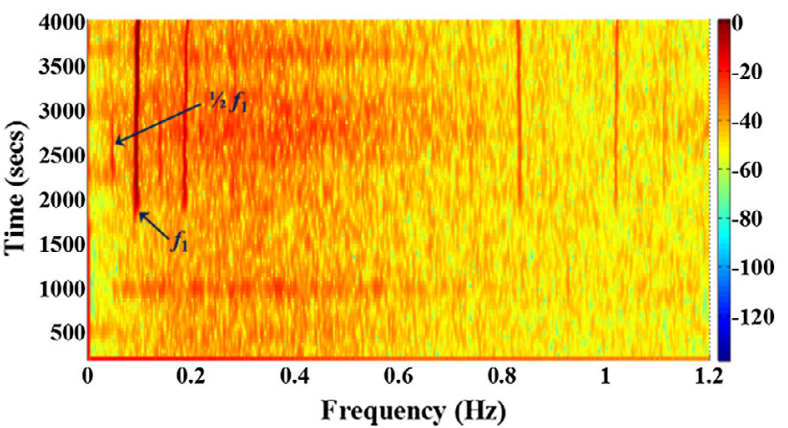

(a)

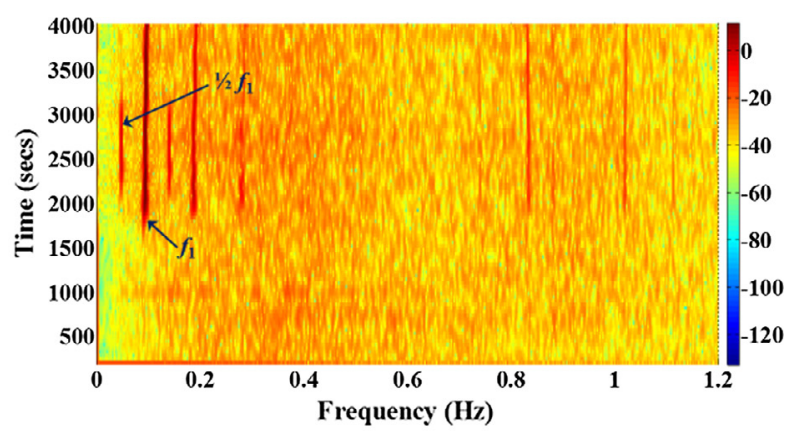

(b)

Fig. 15. Time-frequency spectra of temperature oscillation at the volume ratio of 0.564 : (a) thermocouple 4 in the fluid; (b) thermocouple 5 in the fluid.
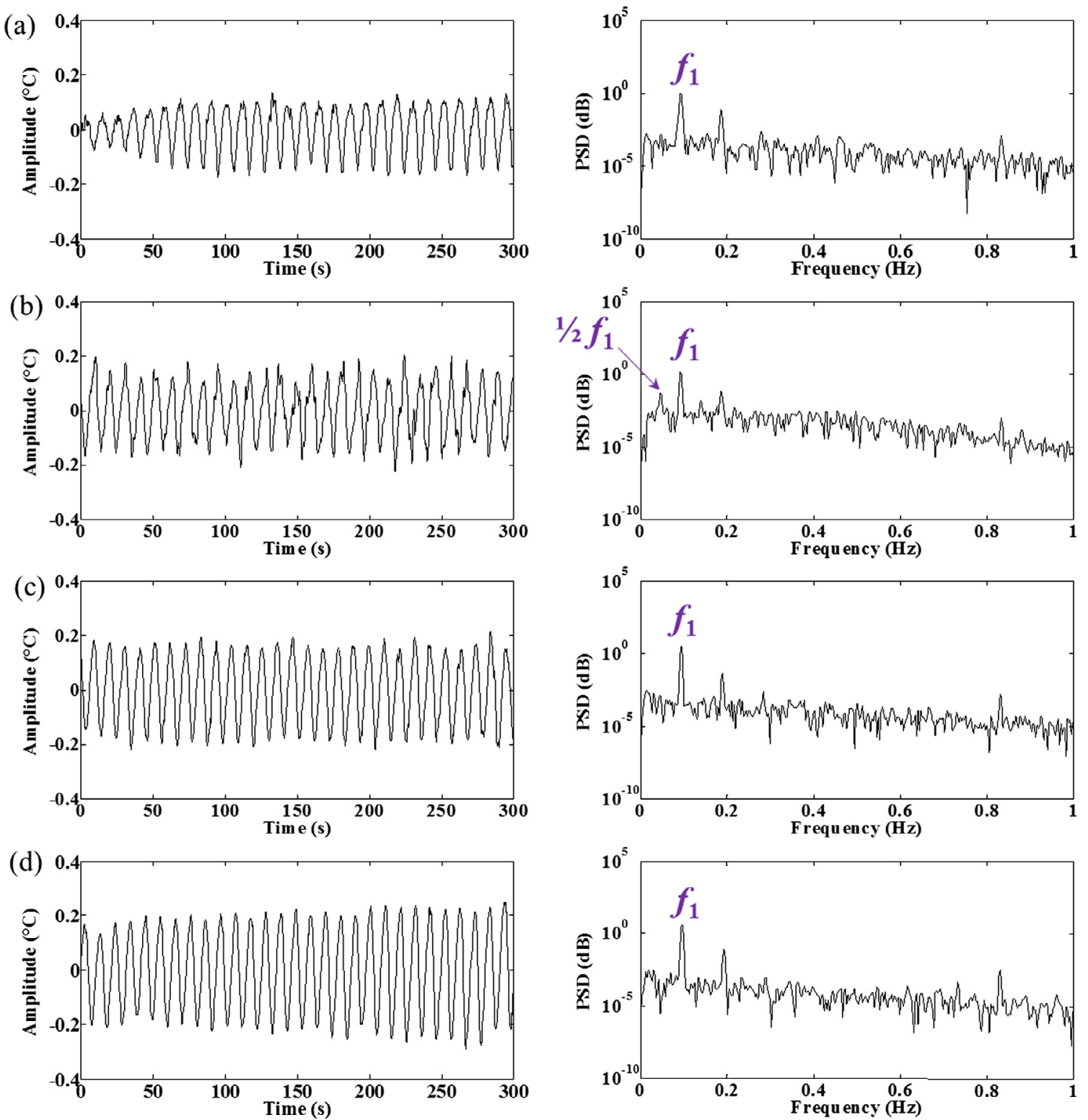

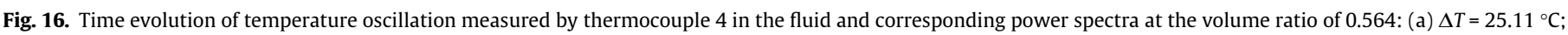
(b) $\Delta T=26.08{ }^{\circ} \mathrm{C}$; (c) $\Delta T=27.04^{\circ} \mathrm{C}$; (d) $\Delta T=28.97^{\circ} \mathrm{C}$

continuously, the oscillation turns back to be periodic, and the fundamental frequency is $0.067 \mathrm{~Hz}$. However, before long the convection turns into aperiodic oscillation again, and lasts until the end of the experiment. The phenomenon that regular periodic oscillation and irregular aperiodic oscillation appear alternately in the convection is the so-called intermittency[33,34] (or intermissions). 

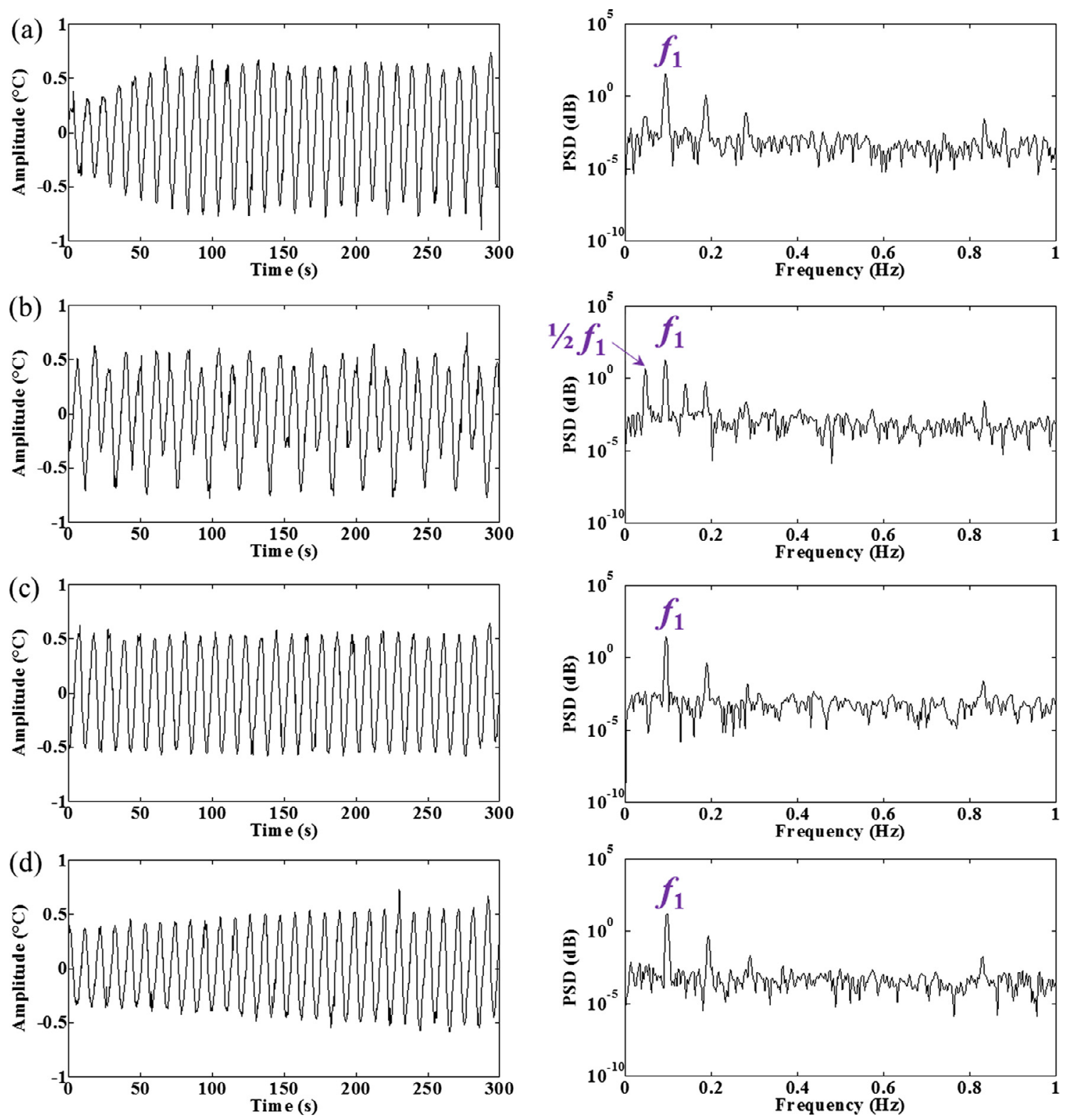

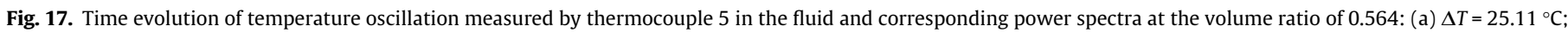
(b) $\Delta T=26.08^{\circ} \mathrm{C}$; (c) $\Delta T=27.04^{\circ} \mathrm{C}$; (d) $\Delta T=28.97^{\circ} \mathrm{C}$.

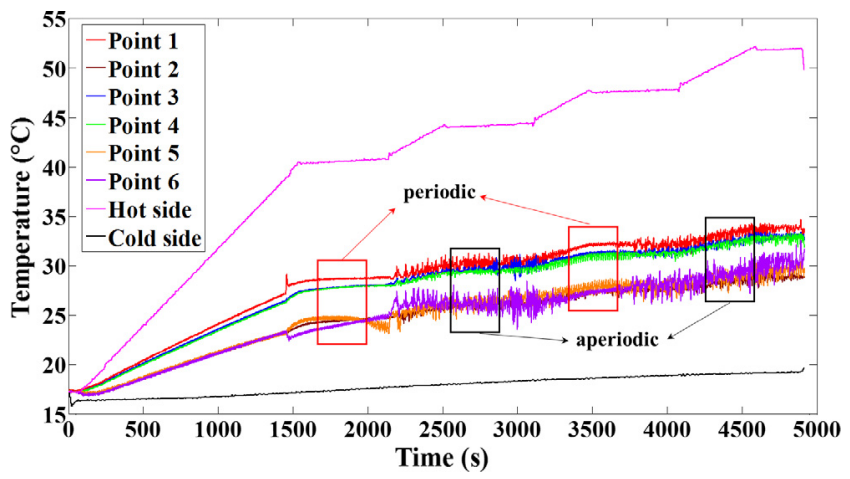

Fig. 18. Time evolution of temperature oscillation measured by thermocouples at the volume ratio of 0.606 .

\section{Conclusions}

SJ-10 recoverable scientific experiment satellite provides us the experimental platform in the microgravity environment, thus we can perform investigations on the volume effect issue of thermocapillary convection in the annular liquid pool, which is hard to conduct on the ground.

The relation curve between the critical temperature difference of start-oscillation and the volume ratio of the fluid in thermocapillary convection is obtained. The critical temperature difference of start-oscillation in thermocapillary convection obtained in space experiments is more than ten degrees lower than that in buoyant-thermocapillary convection obtained in ground-based experiments, which indicates that thermocapillary flow driven by the surface tension is more liable to lose stability and transit from the steady state to the oscillatory state. After the convection starts oscillating, the frequency of oscillation in space experiments is less than that in ground experiments in one order of magnitude, which 
Table 2

Comparison of experimental results in the space and that on the ground.

\begin{tabular}{|c|c|c|c|c|}
\hline $\begin{array}{l}\text { The experimental } \\
\text { type }\end{array}$ & $\begin{array}{l}\text { The onset } \\
\text { temperature } \\
\text { difference }\end{array}$ & $\begin{array}{l}\text { The frequency of } \\
\text { oscillation }\end{array}$ & The transition route & The phase of bifurcation and transition \\
\hline $\begin{array}{l}\text { The ground-based } \\
\text { experiment }\end{array}$ & $25-36^{\circ} \mathrm{C}$ & $\begin{array}{l}10-1 \mathrm{~Hz} \text { order of } \\
\text { magnitude }\end{array}$ & $\begin{array}{l}\text { Quasi-periodic route, period-doubling } \\
\text { bifurcation, and intermittency }\end{array}$ & $\begin{array}{l}\text { Bifurcation appears shortly after the periodic oscillation } \\
\text { starts, then develops into chaos }\end{array}$ \\
\hline $\begin{array}{l}\text { The space } \\
\text { experiment }\end{array}$ & $12-25^{\circ} \mathrm{C}$ & $\begin{array}{l}10-2 \mathrm{~Hz} \text { order of } \\
\text { magnitude }\end{array}$ & $\begin{array}{l}\text { Quasi-periodic route, period-doubling } \\
\text { bifurcation, and intermittency }\end{array}$ & $\begin{array}{l}\text { Stays in steady periodic oscillation state, and bifurcation } \\
\text { appears at large temperature difference }\end{array}$ \\
\hline
\end{tabular}

is a significant reason why thermocapillary convection can maintain a steady periodic oscillation within a large range of temperature difference.

For study on the mechanism of the convection transition, the linear heating mode and the step heating mode have been adopted in space experiments, and transition processes and transition routes have been acquired by both heating modes. Transition characteristics in thermocapillary flow have been focused, especially physical phenomena and laws after the convection starts oscillating. Temperature oscillation of the fluid during the process of destabilization and transition in thermocapillary flow have been studied, and the oscillation mechanism and the process of bifurcation transition in thermocapillary convection have also been analyzed. In space experiments, it is found that thermocapillary convection generally stays in the steady periodic oscillation state, while transitions appear in the condition when the temperature difference between two sides of the liquid layer is large. Three types of transition routes have been observed, including the quasi-periodic route, the period-doubling bifurcation and intermittency. All these three transition routes could be acquired likewise in ground-based experiments, however, thermocapillary flow in the microgravity environment is harder to transit to the phase of bifurcation, and the flow even returns to the periodic oscillation state after the period-doubling bifurcation appears. It is totally different from the transition process in buoyant-thermocapillary convection on the ground, which is the transition from the periodic state to the transition, and then to chaos in a short time.

Characteristics of thermocapillary convection in the space compared with characteristics of buoyant-thermocapillary convection on the ground are listed in Table 2. When the surface tension is the only controlling factor in thermocapillary convection, though the flow is liable to start oscillating, it shows a steady oscillation state.

\section{Conflict of interest}

The authors declared that there is no conflict of interest.

\section{Acknowledgments}

There are many participants who have contributed to the work presented in this paper. Besides the authors listed above, Di Wu, Pu Zhang, Zhiyi Han, Liang Hu, Jianwu He, Longsheng Duan, Yinyin $\mathrm{Su}$, and Mingzhu Hu participated in the experimental monitoring during the process of this space experiment and the processing of spatial experimental data; Li Zhang and Di Zhang carried out a large quantity of research work on thermocapillary convection in the annular liquid pool in ground-based experiments; Zao Jiang at Neusoft, Yongli Yin, Jingsong Yang, Sifang Zhao and Shuangbo Li at China Astronaut Research and Training Center participated in developing the space experimental equipment. Great appreciations to all participants.

This work is funded by the National Natural Science Foundation (U1738116), China and by the Strategic Priority Research Program on Space Science, Chinese Academy of Sciences, China: SJ-10 Recoverable Scientific Experiment Satellite (Grant No. XDA04020405 and XDA04020202-05).

\section{Appendix A}

See Table A.1.

Table A.1

Space experimental conditions.

\begin{tabular}{|c|c|c|c|c|}
\hline Volume ratio & $\begin{array}{l}\text { Critical temperature } \\
\text { difference }\left({ }^{\circ} \mathrm{C}\right)\end{array}$ & $\begin{array}{l}\text { Fundamental frequency } \\
\text { of start-oscillation }(\mathrm{Hz})\end{array}$ & Heating condition & $\begin{array}{l}\text { Notes (experimental } \\
\text { sequence number) }\end{array}$ \\
\hline 0.423 & 16.03 & 0.159 & Linear heating mode, maximum temperature difference of $25^{\circ} \mathrm{C}$ & 15 \\
\hline 0.506 & 19.90 & 0.096 & Step-heating mode $\left(24^{\circ} \mathrm{C}, 27^{\circ} \mathrm{C}, 30^{\circ} \mathrm{C}, 34^{\circ} \mathrm{C}\right)$ & 10 \\
\hline 0.564 & 25.11 & 0.092 & Step-heating mode $\left(26^{\circ} \mathrm{C}, 27^{\circ} \mathrm{C}, 28^{\circ} \mathrm{C}, 30^{\circ} \mathrm{C}\right)$ & 11 \\
\hline 0.600 & 20.23 & 0.082 & Linear heating mode, maximum temperature difference of $25^{\circ} \mathrm{C}$ & 1 \\
\hline 0.606 & 23.13 & 0.070 & Step-heating mode $\left(24^{\circ} \mathrm{C}, 27^{\circ} \mathrm{C}, 30^{\circ} \mathrm{C}, 34^{\circ} \mathrm{C}\right)$ & 9 \\
\hline 0.634 & 25.76 & 0.058 & Linear heating mode, maximum temperature difference of $35^{\circ} \mathrm{C}$ & 12 \\
\hline 0.677 & 23.96 & 0.061 & Linear heating mode, maximum temperature difference of $25^{\circ} \mathrm{C}$ & 2 \\
\hline 0.692 & 25.08 & 0.061 & Step-heating mode $\left(19^{\circ} \mathrm{C}, 22^{\circ} \mathrm{C}, 26^{\circ} \mathrm{C}, 31^{\circ} \mathrm{C}\right)$ & 8 \\
\hline 0.724 & 25.55 & 0.064 & Linear heating mode, maximum temperature difference of $35^{\circ} \mathrm{C}$ & 13 \\
\hline 0.777 & 18.79 & 0.070 & Linear heating mode, maximum temperature difference of $25^{\circ} \mathrm{C}$ & 3 \\
\hline 0.809 & 18.26 & 0.052 & Step-heating mode $\left(19^{\circ} \mathrm{C}, 22^{\circ} \mathrm{C}, 26^{\circ} \mathrm{C}, 31^{\circ} \mathrm{C}\right)$ & 7 \\
\hline 0.834 & 18.91 & 0.055 & Linear heating mode, maximum temperature difference of $25^{\circ} \mathrm{C}$ & 4 \\
\hline 0.855 & 19.35 & 0.052 & Linear heating mode, maximum temperature difference of $40^{\circ} \mathrm{C}$ & 23 \\
\hline 0.905 & 16.80 & 0.052 & Step-heating mode $\left(14^{\circ} \mathrm{C}, 18^{\circ} \mathrm{C}, 23^{\circ} \mathrm{C}, 29^{\circ} \mathrm{C}\right)$ & 6 \\
\hline 0.940 & 14.04 & 0.046 & Linear heating mode, maximum temperature difference of $25^{\circ} \mathrm{C}$ & 5 \\
\hline 0.993 & 14.95 & 0.046 & Linear heating mode, maximum temperature difference of $25^{\circ} \mathrm{C}$ & 16 \\
\hline 1.045 & 15.55 & 0.043 & Linear heating mode, maximum temperature difference of $35^{\circ} \mathrm{C}$ & 22 \\
\hline 1.053 & 15.50 & 0.046 & Linear heating mode, maximum temperature difference of $25^{\circ} \mathrm{C}$ & 17 \\
\hline 1.113 & 14.71 & 0.043 & Linear heating mode, maximum temperature difference of $25^{\circ} \mathrm{C}$ & 18 \\
\hline 1.129 & 13.91 & 0.040 & Linear heating mode, maximum temperature difference of $25^{\circ} \mathrm{C}$ & 21 \\
\hline 1.173 & 12.61 & 0.037 & Linear heating mode, maximum temperature difference of $25^{\circ} \mathrm{C}$ & 19 \\
\hline 1.220 & 12.22 & 0.037 & Linear heating mode, maximum temperature difference of $25^{\circ} \mathrm{C}$ & 20 \\
\hline
\end{tabular}




\section{References}

[1] S. Ostrach, An experimental study of surface-tension induced convection at reduced gravity, B. Mater. Sci. 4 (2) (1982) 133-147.

[2] M.K. Smith, S.H. Davis, Instabilities of dynamic thermocapillary liquid layers. Part 1. Convective instabilities, J. Fluid Mech. 132 (1983) 119-144.

[3] Y. Kamotani, S. Ostrach, S. Lowry, An experimental study of heat induced surface-tension driven flow, Mrs Proc. (1981) 161-172.

[4] Y. Kamotani, S. Ostrach, L.W. Wang, Experiments on natural convection heat transfer in low aspect ratio enclosures, AIAA J. 21 (2) (1983) 290-294.

[5] E. Favre, L. Blumenfeld, F. Daviaud, Instabilities of a liquid layer locally heated on its free surface, Phys. Fluid 9 (1997) 1473.

[6] N. Mukolobwiez, A. Chiffaudel, F. Daviaud, Supercritical Eckhaus instability for surface-tension-driven hydrothermal waves, Phys. Rev. Lett. 80 (1998) 4661.

[7] M.F. Schatz, G.P. Neitzel, Experiments on thermocapillary I nstabilities, Annu. Rev. Fluid Mech. 33 (1) (2001) 93-127.

[8] T. Qin, Željko Tuković, R.O. Grigoriev, Buoyancy-thermocapillary convection of volatile fluids under atmospheric conditions, Int. J. Heat Mass Transfer 75 (2014) 284-301.

[9] T. Qin, Željko Tuković, R.O. Grigoriev, Buoyancy-thermocapillary convection of volatile fluids under their vapors, Int. J. Heat Mass Transfer 80 (80) (2015) 3849.

[10] T. Qin, R.O. Grigoriev, The effect of noncondensables on buoyancythermocapillary convection of volatile fluids in confined geometries, Int. J. Heat Mass Transfer 90 (2015) 678-688.

[11] R.O. Grigoriev, T. Qin, The effect of phase change on stability of convective flow in a layer of volatile liquid driven by a horizontal temperature gradient, J. Fluid Mech. 838 (2017).

[12] L. Zhang, L. Duan, Q. Kang, An experimental research on surface oscillation of buoyant-thermocapillary convection in open cylindrical annuli, Acta Mech. Sinica 30 (5) (2014) 681-686.

[13] L.S. Duan, L. Duan, H. Jiang, Q. Kang, Oscillation transition routes of buoyantthermocapillary convection in annular liquid layers, Microgravity Sci. Technol. (2018) 1-12.

[14] Q. Kang, L. Duan, L. Zhang, et al., Thermocapillary convection experiment facility of an open cylindrical annuli for SJ-10 satellite, Microgravity Sci. Technol. 28 (2) (2016) 123-132.

[15] J.P. Gollub, S.V. Benson, Many routes to turbulent convection, J. Fluid Mech. 100 (1980) 449-470.

[16] D. Mukutmoni, K.T. Yang, Rayleigh-Bénard convection in a small aspect ratio enclosure 1. Bifurcation to oscillatory convection, J. Heat Transfer Trans. ASME 115 (2) (1993) 360-366.

[17] D. Mukutmoni, K.T. Yang, Rayleigh-Bénard convection in a small aspect ratio enclosure 2. Bifurcation to chaos, J. Heat Transfer Trans. ASME 115 (2) (1993) 367-376.
[18] D. Mukutmoni, K.T. Yang, Thermal-convection in small enclosures - an atypical bifurcation sequence, Int. J. Heat Mass Transfer 38 (1) (1995) 113-126.

[19] Z.M. Tang, W.R. Hu, Fractal feature of oscillatory convection in the half-floating zone, Int. J. Heat Mass Transfer 38 (17) (1995) 3295-3303.

[20] F. Stella, E. Bucchignani, Rayleigh-Bénard convection in limited domains: Part 1 - Oscillatory flow, Numer. Heat Tr. A-Appl. 36 (1) (1999) 1-16.

[21] E. Bucchignani, F. Stella, Rayleigh-Bénard convection in limited domains: Part 2 - Transition to chaos, Numer. Heat Tr. A-Appl. 36 (1) (1999) 17-34

[22] S. Rahal, P. Cerisier, C. Abid, Transition to chaos via the quasi-periodicity and characterization of attractors in confined Benard-Marangoni convection, Eur. Phys. J. B 59 (4) (2007) 509-518.

[23] Z.W. Chen, Y.S. Li, J.M. Zhan, Double-diffusive Marangoni convection in a rectangular cavity: Onset of convection, Phys. Fluids 22 (2010) 034106.

[24] Y.S. Li, Z.W. Chen, J.M. Zhan, Double-diffusive Marangoni convection in a rectangular cavity: Transition to chaos, Int. J. Heat Mass Transfer 53 (23/24) (2010) 5223-5231.

[25] E. Bucchignani, D. Mansutti, Horizontal thermal convection in a shallow cavity: oscillatory regimes and transition to chaos, Int. J. Numer. Method H. 10 (2) (2000) 179-195.

[26] E. Bucchignani, D. Mansutti, Horizontal thermocapillary convection of succinonitrile: steady state, instabilities, and transition to chaos, Phys. Rev. E 69 (5) (2004) 056319.

[27] K. Li, B. Xun, W.R. Hu, Some bifurcation routes to chaos of thermocapillary convection in two-dimensional liquid layers of finite extent, Phys. Fluids 28 (2016) 054106.

[28] P. Zhu, L. Duan, O. Kang, Transition to chaos in thermocapillary convection, Int J. Heat Mass Transfer 57 (2013) 457-464.

[29] H. Jiang, L. Duan, Q. Kang, A peculiar bifurcation transition route of thermocapillary convection in rectangular liquid layers, Exp. Therm. Fluid Sci. 88 (2017) 8-15.

[30] W.R. Hu, Z.M. Tang, Thermocapillary convection in floating zones, Appl. Mech. Rev. 61 (2008) 010803-1-010803-15.

[31] W.R. Hu, Z.M. Tang, K. Li, Floating zone thermocapillary convection, Adv. Mech. 39 (3) (2009) 360-377.

[32] Y. Aa, K. Li, Z.M. Tang, Z.H. Cao, W.R. Hu, Period-doubling bifurcations of the thermocapillary convection in a floating half zone, Sci. China Tech. Sci. 53 (9) (2010) 1681-1686.

[33] P. Berge, Y. Pomeau, C. Vidal, Order within Chaos: Towards a Deterministic Approach to Turbulence, John Wiley \& Sons, New York, 1984.

[34] Y. Pomeau, P. Manneville, Intermittent transition to turbulence in dissipative dynamical systems, Commun. Math. Phys. 74 (2) (1980) 189-197. 